\title{
The everyday enchanted we do not acknowledge
}

\section{Introduction}

What do you think of dreams, music and imagination? Are they an important part of our lives, or to be side-lined as not part of the 'rational selves' we tend to claim for ourselves as part of the scientific revolution? By now there are moves afoot, to look more closely at what could be called 'alternative' or 'heightened' consciousness, the kind we rather seldom acknowledge but in some way gain access to when we dream, are 'carried away' by music, or are 'inspired' to create some work of visual or sonic art. Many feel-though seldom confessthat at times they have some kind of contact with the dead or (and not by ordinary earthly means) with others far away. Or again there is the felt cintact with the supernatural/God/fate (whatever name you like): what else is assumed, if only subliminally, in praying, in sending bkessings' or good wishes'-all quite ordinary rather unthinking habitsor wishing someone 'good luck'? ${ }^{1}$

Most people, too, have some way or another felt what have been called (there is no easy name) the 'vibes' of some ancient sacred place, the feel of some kind of psychic awareness during yoga (or the like), or of non-bodily therapeutic healing. Above all, it seems, us the near, beyond all of being in some way transported by music. Such things are common in 'everyday life yet at the same time all seldom explicitly recognised. Too familiar and obvious, perhaps, to be noticed as really 'there'. ${ }^{2}$ This chapter-which let me say in advance some will find controversial- examines and in the process deepens our incipient awareness if the hidden layers of the ordinary by taking such experiences seriously. It seeks to throw more light of what is going on: on what is, however little talked about, all the time there for at least some human being, and perhaps, at any rate potentially, for all. It is not only the poets who live in the fire of inspiration and of being somehow 'beyond; themselves or only the people of faraway or long ago that have experience of what has been called by such terms as the sixth sense or extra-sensory perception (a common enough concept to have acquired its own acronym of ESP), yet still mostly shy away from seeing this as a possible aspect of ordinary living. ${ }^{3}$

Let us begin from the critical subject of dreaming, a mode that keeps emerging in myth and literature as throughout life. It is both 'ordinary', an everywhere familiar and understood concept, and also the fundamental magical path to the 'hidden' to be found, also, the experiences of death, of music, and of both shared and individual consciousness.

Few of those educated in a western tradition will fail to recall Coleridge's Kubla Khan and the ever-cursed 'man from Porlock' who interrupted and spoiled poet's dream-memory of the poem. Not so many know that Montezuma was led by dreams and divination, and writers from mediaeval saints and scholars to Mark Twain in more recent times have famously been inspired by dreams. Einstein too, it seems, and perhaps Newton and Descartes, not to speak of the preSocratic philosopher-scientists were influenced by dreams as much as by this-world everyday science. In political life too. ${ }^{4,5}$ Churchill insisted, no doubt to his aides' despair, in getting undressed and into bed every afternoon and it was his dreams that guided his war policies; so too with Joan of Ark and Abraham Lincoln. Classical and mediaeval authors took dreams seriously, if also noting that noting
Volume 2 Issue 6 - 2018

\author{
Ruth Finnegan \\ Department of Social Sciences, The Open University, UK
}

Correspondence: Ruth Finnegan, Department of Social Sciences, The Open University, Milton Keynes MK7 6AA, UK, Email r.h.finnagan@open.ac.uk

Received: December 18, 2017 | Published: December 17, 2018

that false dreams could come through 'the gates of horn' as against those coming by 'gates of ivory'. For them as for many modern scholars dreams are not so much misleading falsehood as another kind of reality, albeit in a different mode of experience. The subject, much studied in antiquity and the middle ages, lost something of its scholarly appeal in more recent centuries with the exception of the enormously influential and mind-opening but, from some recent viewpoints, misleadingly reductionist psychological perspectives of Freud and Jung (especially Freud). By now the subject is receiving more attention, both popular (sometimes, but far from invariably, uncritical) and academic, and is widely studied from a variety of such disciplines as psychology, anthropology, neuroscience and cultural history. ${ }^{6-10}$

The topics of dreaming, death experiences and shared consciousness are now popular subjects for debate. We see a flood best-selling volumes, many by hard-nosed senior scientists (even the American government and army take telepathy seriously). The interest can also be linked to the contemporary commitment to religion and religious interest-not necessarily within established churches but to spirituality and emotion and an often-unrecognised musical effervescence that goes with it, both strongly connected to the study or at any rate the awareness of the nature of heaven and of consciousness. ${ }^{11-14}$

Throughout the world we see the proliferation of a growing number of centres devoted to the subject, and any army worth its salt is interested in remotely controlled minds: Senior figures in science and arts propound its relevance readers flock to their ideas, journals abound with names like Neuro-whatever, Cognitive this or that, Parapsychology, Consciousness. Books, manuals and speculations about dreams, reliable and not, throng the internet, books on telepathy and return from the dead rush into the best-seller lists, studies of telephone telepathy are to be found in university psychology departments ('I was just thinking of you when the phone went...', 'I knew it was you phoning, and so did my dog...'), experiments are conducted with all the greater rigour because of the controversies, and even among the top research fund-givers 'consciousness' (never of course referred to as telepathy) has become a fashionable topic for scientific research. ${ }^{15-17}$ In consequence there are by now a plenitude of serious studies of the nature and images of dream-carriers, of twin communication and analyses in psychology, research into the brain; aided by the sometimes neglected findings of and through MRI; neuro=scientific and cognitive studies; and, from a different but equally rich direction, wisdom from Hinduism, Buddhism and Confucianismindeed from eastern and ancient seers generally. In our own culture(s) we find candid biographies/autobiographies (such as the pianist Janis 
Byron's extraordinary-yet in a way irdinary, everyday-paranormal experiences with Chopin), recounting encounters with the non-local and non-everyday dimensions of their lives. The experiences of psychotherapy; studies of ageing, hypnosis and self-healtng; the long tradition of Buddhist meditation; The Society of Friends' (Quakers') meditative meetings for worship, and the silent monastic orders - all prove rich and long-enduring if too often neglected perspectives. ${ }^{18}$

Nowadays therefore anthropologists, psychologists, writers of literature and historians (among others) have much to say about dreaming and its communicative and thinking power. Many cases have by now been documented, well-known too in antiquity, of the origins of literature, ${ }^{19}$ music and scientific theory lying in dreamsnot just Coleridge's Kubla Khan but Milton's epics, my own novels (to my surprise), Brahms' and Mozart's compositions, the theory of relativity, the double helix (probably) and, at a more mundane level;, the invention of the sewing machine. ${ }^{20}$

In dreaming, it seems, often with even greater immediacy than the experience of death, telepathy or even music, we humans have long had a recognised entry to the entrancing experience and consciousness of the noosphere. It is hard indeed to measure since it is all internal and subjective, with no outside observers possible of the kind found in some other spheres such as the narrated experience of returning from the dead. Also many people are reluctant to talk about their dreams. But there is now a large literature on the subject. It appears that dreams, including visionary and prophetic dreams, are not at all uncommon..$^{21}$ In the last few years I too have certainly experienced dreams that lead me to, or rather find me within, some sphere beyond the ordinary time and space. Mentioning my own experience frequently leads others to break their reluctance to speak out: they too have dreamed in a domain out of our ordinary time and space. Dreams are also frequently referred to in fiction, letters, memoirs and poetry, and very often in past centuries. ${ }^{22-24}$ Now and in the past dream interpretation-manuals are best sellers (now on the web, with constant advertisements from those offering to interpet your dreams for you). ${ }^{25}$ It seems fair to conclude that dreaming is a fairly common, though not universal (not consciously at any rate), phenomenon among human beings.

A more objective, and perhaps unique attempt at uncovering the incidence dreams cross-culturally has recently been carried out by two anthropologists in Holland, G-B-a regular experience of precognitive dreams since childhood, and W-S-- an immigrant from Thailand who had experienced such dreams intermittently and interprets them according to his Buddhist beliefs in reincarnation. The two drew on the unexpected offer of a number of individual volunteers to share their experiences, all highly educated, currently studying at postgraduate level. ${ }^{26}$ From their responses became clear that such dreams are known across many cultures-in their case European, Eastern (including China and Thailand), and north American as well as across a range of western and non-western originated religions. They see their experience as inhabiting a kind of grey zone between telepathy, prophecy, and dream management in an area with several labels-such dreams are known across the world-but that has become widely known as 'déja-vu' (already-seen dreams) and then there is people's consciousness of and around death, Death is the end is it not? The truly and absolutely hidden? But new views of consciousness and the widespread experience of survival and of communication between the dead and the living tell us otherwise. Startling to conventional wisdom, the evidence of survival and of continuing interaction is overwhelming, throwing new light on the concept and actuality of consciousness beyond what we think of as everyday reality. ${ }^{27}$ Heaven- sent voices seem to be constantly with us. Often ignored in the academic literature the subject is now receiving attention, more at any rate than in the last couple of centuries (wiser than us, it was taken more seriously by classical and mediaeval writers, even the once despised but actually often insightful Victorian scholars). There are now a multitude of studies, many of them by hard-nosed scientists and neurosurgeons who, late in life, have, almost against their best will, been converted through personal experience or scientific study to confronting the hard evidence. We must not blink the costs in human suffering of course with some anodyne vision of 'all is well'. But set against that we meet the equally human tales of return and immortality in the repeating cycles of dying, death, venture into heaven, messages and appearances to the earthly living whether in dreams, or in some other sensible form. The dying, it seems, have many dreams: predicting, threatening, consoling, posing problems that demand solution summing up their lives, reassuring. Those who work in hospitals and hospices, above all their chaplains, ${ }^{28-30}$ are the confidants of these dreams in some cases taking them as a subject of study. 'Hiroshi', for example, diagnosed with terminal lung cancer when he was twenty-eight years old, knew that he was dying. He was desperate, terrified that his Japanese ancestors were angry with him for becoming a Christian and abandoning their religion. But a week before he died, he told his carers that he had had a marvellous dream, 'so real that it must have happened:

The doorbell rings, and I answer it. There stand my aged grandparents, very short, neatly dressed, bowing and smiling. They slip off their shoes in the traditional Way, enter the room, and hold forth two very large bouquets of pinkish orchids. I bow deeply and smile in return at their happy faces. 1 accept the bouquets, and that was the end of the dream. ${ }^{31}$

Sometimes the dreams came in the form of music, as in the lovely negro-spiritual:

Swing low sweet chariot

Coming for to carry me home,

Swing low sweet chariot,

Coming for to carry me home ...

Moving on, it is striking how many accounts there are of visitations by the dying on their way to another world, something I have myself experienced: once from my dyuing mother, once from my oldest friend, visiting me in farewell (but not goodbye for ever) on their way to heaven. After many years on earth, a dying person may not wish to relinquish their life on earth without some sign, perhaps some urgent practical message to a loved one, or at least a sign of farewell. Thus we hear of the message from a dying, perhaps by then dead, colleague heard by a public accountant in Oregon. Early one morning she was pinched awake to see him standing by her bed. 'I'm sorry Clare. I didn't make it'. He added 'goodbye', as if forever. Then he just vanished. I sat on the edge of the bed and contemplated his message. I was wondering 'What on earth?' Then my clock radio witched on with the early morning news. they announced that Hugh's seaplane had gone down in the Columbia river the day before. He didn't make it ashore and was drowned. ${ }^{32}$

Many are such tales in both the past and the fully attested and witnessed present. Sometimes it is not so much an intimation during the dying transition or a dream but what is felt as a direct message from a loved now-in-heaven dead soul bringing comfort or information for the survivor(s). In fact accounts of messages from the dead are legion 
and have been so, apparently, throughout history. And then there are the returnees from death or, as many of them put it, from heaven. This no doubt sounds impossible, fantastic. But the subject is one of profound concern to humanity, always has been, always will be. Return from death appears in humanity's greatest myths, illustrated in Joseph Campbell's The Hero with a Thousand Faces ${ }^{33}$ and deep, it seems, in the psyche of our humanity, inspired-who knows whence? Remember the Welsh Powys visiting and returning from Anwin, the underworld, in the Mabinogion, the evergreen Greek stories of Persephone's return and of Alcetsis brought back from Hades by the burlesque hero Heeracles, of Odysseus and Orpheus, and of kings like Arthur returning after death to check their earthly kingdoms. We can recall too the iconic Christian tale of a resurrection. The returnfrom-death narrative, it seems, is a seminal myth known throughout the world and forever. But it is more than 'just' a myth if by that term we imply a delusion, a misconception, even a fabrication. There are plentiful first-hand accounts of the experience of dying and returning, reluctantly, to live again on this earth. It seems that there are thousands, indeed millions, of people worldwide with stories to tell, communicating what they had of themselves seen, heard and felt. As a result there are thousands of death-and-return reports, as apparently there have been since the beginning of time. ${ }^{34}$

The evidence is extensive and compelling in both factual and epistemological terms through, for instance, the recent surge of interest by philosophers, physicists, information technologists, medics, and social- and neuro-scientists in consciousness studies, robotics and cognitive issues The experience, it seems, is much more widespread than would appear from the conventional wisdom and it is now at last 'done to talk about it!' So there are now many scientific accounts of the so-called 'near-death experience'. ${ }^{35}$ It has even acquired its own acronym of NDE (I myself prefer to call it death-and-return experiences, for it is often actual, and nowadays clinically verified, death not 'near' death, but the acronym is nevertheless a useful one). Interpretations incompatible with the ruling physicalist and reductionist stance are conventionally ruled out of account. Indeed even mentioning it is impossible in certain circles so that it is often only at the end of their careers, after retirement, that scientists come out with what they have been doing and complement the scientific accounts by the first-hand human tales of contact with the dead and their experience of, as Annamaria Hemingway ${ }^{36}$ has it, "the eternal continuum of consciousness'. That brings us to the emotive subjectsor perhaps it is really one, related, subject-of inspiration, trance and music. Let us return to Coleridge's dream and the mysterious verses that remain: Kubla Khan or, a vision in a dream. A Fragment. In Xanadu did Kubla Khan A stately pleasure-dome decree: Where Alph, the sacred river, ran Through caverns measureless to man Down to a sunless sea. So twice five miles of fertile ground with walls and towers were girdled round; and there were gardens bright with sinuous rills, where blossomed many an incense-bearing tree; and here were forests ancient as the hills, Enfolding sunny spots of greenery.

\section{Dream and trance-like indeed}

There are many such cases. Less celebrated than Coleridge's, we hear of countless poems and music created in some mode of trance by their composers. There is a sense in which creativity, nowadays a topic of such interest, is often the fruit of some other plane existence than the workaday world, the ordinary one we know. Siberian epic poets were endowed with a kind of mysterious gift bestowed on the person of the singe by a prophetic call from on, the lone sailor was tranced in the ether's 'Song's End' before his death, ${ }^{37}$ Paul and others experienced their enchanted (as it were) 'Damascene moments' of revelation in a vision from some somewhere beyond this world's ways on the road to a revolutionary turn in lives. My own novel and its sonic, innovative, words and rhythms arrived from somewhere outside me, without, it seemed, conscious thought or planning but, again in that trancelike liminal state between sleeping and waking. As for the London poet and fiction writer Denise Saul, poems too arrive from somewhere beyond me, ready-made in their appropriate genres, rhythms and sonic assonances. ${ }^{38}$

And then there can be the sudden, dreamlike, strike of inspiration, duty even, that similarly comes somehow from beyond. An artistpriest speaks of the 'epiphany moment' led him suddenly to see in a biblical text often before read but now for the first time standing out as a 'divine revelation' -permission to integrate his dual mission of both painting and ministry. We know too of Milton's Paradise Lost, Mark Twain's speeches, poetry and song coming from some kind of trance or altered consciousness rather than workaday routines. Music too, like the dreams (dreams-we never, it seems, get away from that mode of consciousness) that inspired Brahms and Mozart-but then, how could the origin of such heavenly beauty be purely mundane? ? $^{39-41}$ Or the baroque violin virtuoso Tartini, so often forgotten. His near unplayable 'Devil's Trills', so the story goes, originated in a pact with the devil who came in a dream to play them to Tartini overnight-and hard enough they were, a movement full of trills ad double stoppings that, forgetting the rest, he still remembered when he awoke. Until Yehudi Menuhin, it is said, Tartini alone could play it-with his six fingered devil-endowed left hand. Music can be treated, rightly, as a crucial if puzzling element in the entrancement and altered consciousness treated in this volume. We too often forget Albert Einstein who, asked about the origin of his theory of relativity-the start of modern science-is said to have replied.

The theory of relativity occurred to me by intuition, and music is the driving force behind that intuition. My parents had me study the violin from the time I was six. My new discovery is the result of musical perception.... I often think in music. I live my daydreams in music.... Imagination is more important than knowledge. Although rather seldom noticed in the context of studies of consciousness, there is serious research that well justifies the inclusion of music. It treats, among other things, the relation of music to dream-revelation, to healing, to psychic energy, the emotions, our sense of structure and rhythm-outcome of the deepest and most enduring, as we have seen, of the human senses, touch-audition. Like dreaming, meditation and the experience-and-return from death, music enables the re-creation of mind and supports the enhanced and altered states of consciousness we term entrancement. ${ }^{42}$ Chanting too is accepted as carrying deep meaning, widely utilised in healing, in meditation, in hypnosis, in shamanic trancing. And who, one might ask, can picture any kind of heaven without its trumpets and its choirs of angels? Music, it turns out, is, both obviously and, to many, unexpectedly, crucial for the subject of this volume. There is much still to be investigated and understood, but even thus far it becomes clear that music is central if we wish to delineate and integrate new approaches to and dimensions of the conscious. Music is an aspect rather seldom taken seriously within the burgeoning scientific literature on human consciousness but is rightly pursued, at least a little, in this volume. ${ }^{43}$ So then to consciousness itself. This, it scarcely needs saying, is a deeply complex and controversial subject which, like the rest of us no doubt, I am far from understanding. But it is worthy of note that it-consciousness-has become a new object of study, building on but challenging the insights that have formed our wareness since the time of Plato and, doubtless, before: after all the pre-Socratics, among others, had much to say on this not least the fluidity of not stepping 
the same river twice, a notion that has returned. And now we see in science and spiritual thinking an opening up to new ideas, new ways of appreciating the nature of consciousness. Much considered over the centuries, the confidence of the twentieth-century science seemed to suggest all was already known and understood: it was forever fixed in a materialist and conquerable universe. Much was indeed known and the fruits of the scientific endeavours of those years are much with us, and to our benefit. But gradually, first since Freud Jung and their collective (if variegated) views of the unconscious-unseen, unheard, un-experimentally proven-then, more decisively with quantum and chaos theory, brain scans, advances in neurology, the new worlds of MRI-comparable only to the new worlds revealed brought by the telescope and microsope-and, most notably, the theory relativity and the elision or conflation of the concepts of time and space the universe has changed-or rather our understanding has been revolutionised. The universe is not as we once assumed material, ourselves mental and spiritual. As a series of research works have shown consciousness runs through all things-animals (little surprise there), plants, the sea, the earth. One consequence is that previously firm notions of causality are breaking up. It is no longer seen as predominantly one-way or single-driven but more a matter, perhaps, of an as yet dimly glimpsed reality already existent out there' irrespective of time and space and yet, somehow in ways we cannot understand, reconcilable with free will and changeability. We see a house and fall in love with it, and for that reason, we surmise, we buy it. But what if the 'cause' of that immediate throb of desire for that house was because we had, were to, would be living in it and loving it in whether in past present or future. A man adores his once-glimpsed love. Was it for that reason that in their 80 s they finally married-or was the causality in some way willed indeed by them both but the other way round? This has to be causality as we usually see it turned on it head, the 'later' causing the 'earlier' rather than the other way. Can it be that there are actualities existent in some dimension that we may not yet have reached in our present lives but is nevertheless already there, the dividing curtain, more, or less, thin at different points in our lives, in trance, in dream, music, traces of our inner, conscious, selves. Allied to this, the 1960s' emphasis on psychedelic drugs has been largely superseded by a much wider interest in the whole range of what are nowadays called 'altered states of consciousness', by now with its own acronym (ASC). Psychologists are now less concerned with the question of the reality of spirits or of their social context but instead look for the universal human psychobiological potentials which are supposedly culture-free and can be reproduced and studied under laboratory conditions. Such research uses neurophysiology (the study of the nervous system)-especially the relationship between drum rhythms and brain-waves - and chemistry, through the study of opiate-Iike compounds called endorphins. New Age and neo-shamanist practitioners share this commitment to the idea of states of consciousness that is independent of particular cultures: although they find some ethnography fascinating moving, they do not wish to be closely tied to all its specific features. Some authors speak of a general religious state of consciousness or of a trance state that encompasses both what are known as shamanism and as possession. Others identify a distinctive shamanic state of trance or ecstasy based on the shaman's experience of soul flight (although some speak of a single 'shamanic state of consciousness', it seems increasingly likely that there are many).

This brings us to telepathy, that difficult term so much better expressed as shared minds or kononia, communion, a word, fittingly from the Greek, with appropriate, it seems, theological as well as philosophical connotations. Here we find a species of somehow 'shared experience irrespective of time and space' and lives, a new views of consciousness that has attracted much interest, both popular and academic (and hard-headed at that). Answers have turned into questions, visions into journeys of expioration. We no longer know just what consciousness is but do know we need to seek to understand it. Well then, what of telepathy-communicating (including at a distance) without reliance on the ordinary normal five senses, Many people of course do not believe this is possible, or at any rate, when asked in public affirm this position. Nor in some moods do I think it could happen on this earth ('heaven' or 'beyond time and space' is a different matter). I too am a scientist and everything I have been taught since a child seems to point the other way and yet ... as we saw earlier there is now serious scientific interest in such topics. This apparent mode of consciousness has even, for some, become a kind of 'ordinary' topic that, complex, subtle and in a way hidden though it is, can in principle be investigated like any other Our own-often quite ordinary- experience attests it too. We know when someone is reading over our shoulder in the underground. It doesn't surprise us or even, unless we start thinking about it, seem strange seem strange-and yet, how can it be possible in our normal scheme of things. Dogs and other pets somehow know when their owners are coming home or are in danger. Hunting herds whether of animals or scattered desert bands keep in touch, somehow non-verbally-and effectively. Must we rule out that potential skill for humans, that supposedly superior species, and say if is, it must be, 'impossible'?

Twins, we generally, accept, are different, 'special' (why? they are human just like the rest of us). We recognize, almost as a matter of course, ordinary, that they often seem to have the power to communicate in ways we do not understand: not necessarily deliberately-or it seems not-but emotionally, spiritually, intensely. Somehow I have seldom met a twin who denies this (yes, one or two), and I always ask. Small babies too, it seems, pre-speech. Is it that twins are together in the womb (what could be closer, more intertwined, more single?), in death and even perhaps in life, chained as one being? I recall the African twins sometimes appear in stories as beings with 'double eyes': insight into and power over the spirit world, those ever- chained beings represented in the powerful Yoruba ibeji figurines and do we not nowadays-even psychotherapists and counselors seem to admit the possibility, no the reality of this-accept some continuing deep connection between living and dead: different, but continuing reinforced in many people's experience, if only at times of dire crisis, by a recourse to prayer. Have we not all known of at least one such enduring, mutually loving, relationship; between mother and dead child, born or unborn; husband and wife; passionate lovers? Why do we exclude it between the living?

Is this then a new or, rather, a somehow hidden and unrecognized but ancient mode of knowledge that is now resurfacing or, rather, being re-discovered? Is it indeed appropriate now to adopt, with Bauman ${ }^{44}$ the idea of 'liquid modernity' or, with Iris of 'fluid knowing' the tpe of knowledge that, as she puts it in a hitherto unpublished paper: Fluid knowledge characterised by its beyondness, its daring spirit and its corporeal but at the same time incorporeal nature signifies the liberty of knowing.... [that] reflects itself in the free exploring spirit and the liberation from boundaries. It allows knowledge to freely flow or be communicated across different cultures, sectors, domains and disciplines. It is a type of knowing without frontier and no limit. It is where there are flows, diffusion, or fusion of knowledges (plural), but there is no centre, neither margins. ${ }^{42}$

What is involved, it seems, is that two intimately linked souls do not so much 'send and receive' specific 'messages' at a distance (tele) as find themselves merged, the thoughts and feelings of the 
one interpenetrating the other: less email message than a dropbox on the cloud. It is kononia, that classic Greek word for sharing and fellowship, rather than a series of discrete messages. By now this is something that I have experienced, unexpected and unsought, in the most first-hand way possible-of my own self, my own primary witness. This has, if with some difficulty and reluctance on my part, radically shaken me out of my earlier convictions-or rather, out of what I must now regard as my earlier ingrained prejudices. ${ }^{45}$ I find some support too in my own, personal, experience. I have a background true, in Quaker experience of silence, in my immersion in music, my Irish ethereally sensitive mother, aided too perhaps the opening of minds that characterizes, or should characterize, the discipline of both anthropology and some knowledge of the insights of the ancient world. None of these are unique experiences. And beyond that I am ordinary, nothing extraordinary to explain my apparently heightened awareness. What encourages me is that every step I have taken, at first slowly and uncertainly, has led to a stronger foundation in the next. Over the last three years I have been learning a new way of perceiving, of living. If this can happen, unintended and unplanned, to someone as ordinary as myself could it not equally apply to others, all others, potentially all human kind? And from what I have learned and what we read here does it not seem that certain activities can enhance our receptivity? I think of already practised arts like meditation; mindfulness' 'alternative' (as they are called) modes of healing and insight and perhaps, divination of the present with is the past and future; respect for our dreams; engagement in spirituality or religion, not least Eastern religions and philosophies aided, for some, by the powers of prayer; communion with nature' and perhaps most of all an acceptance of what we experience and-or is this my Quaker background showing?-the exercise of silence and waiting. Might we not conclude that it is time to confront our fears of the chaos of change and address the revolutionary questions of whether humankind is after all more capable than we have assumed to enter the heightened realm of consciousness? Are we now due for the next unveiling, crowning the half millennium that has so often in the past marked a turning point, a new revelation? It is hard not to believe so. Already, it might be added, we accept electronic and radio waves, sound waves too, unimaginable magic to earlier generations. What new waves of consciousness are hiding out there, awaiting only our recognition, our acceptance of them as, after, 'ordinary', part of our everyday living? Can we doubt that we have resources which, using what terminology and attribution of cause we wish, are given for our celebration and understanding. What new concepts will we yet attain of brain and mind, of our communicative and experiential powers, or of the nature and potential of human beings through the lengthening millennia of human history?

At this time of, perhaps, revolutionary change we would do well not to ignore our hidden depths of our rich human heritage, continuing alongside our widening experience of the ethereal noosphere that has always been there: our heritage of written, spoken and electronic language; visual imagery; dance; the many modes of communication technologies; music and, allied to that and specially lose to my heart, song. And then emerging into our awareness at last-a shared consciousness that, again, has always to an extent been engrained in human life through trance, dream, music allowing-by whatever name-a glance of heaven. Is it in the end too controversial to suggest this new uncurtaining through dreamed experiences of heaven and telepathic communication can, alongside ancient and eastern insights, be counted as something, different indeed, but with its own reality? I think of a beautiful piece of woven cloth, or a picture, in which we suddenly, or perhaps gradually see the pattern in the colours, the design, in what at first seemed random, the meaning that had always been there, but only now, because we have properly looked, unveiled to our eyes. Or like a chord we had heard from our childhood but have never till now detected the inner notes that carry its harmony, its magicality. Again it had always been there, just hidden from our slow perception. There is so much 'ordinary' and usual in what, in our blindness, might seem hidden and mysterious; so much hidden within and beneath our ordinary everyday lives.

\section{Acknowledgments}

None.

\section{Conflicts of interest}

The author declares that there is no conflict of interest.

\section{References}

1. Barrett Deirdre. The Committee of Sleep. How Artist, Scientists, and Athletes Use Dreams for Creative Problem-Solving. Warsaw: Oneiroi Press; 2001. 224 p.

2. Becker J. Deep Listeners: Music, Emotion, and Trancing. Bloomington: Indiana University Press; 2004. 26 p.

3. Blacking John. How musical is Man? Seattle: University of Washington Press; 1973. $132 \mathrm{p}$

4. Blacking John. Reminiscences. Popular Music. 1991;10(2):219-229.

5. Bruner Jerome. Actual Minds, Possible Worlds. Cambridge MA: Harvard University Press; 1987. 222 p.

6. Bulkeley Kelly. Dreaming beyond Death. A Guide to Pre-Death Dreams and Visions. Boston: Beacon Press; 2005. 152 p.

7. Bulkeley Kelly, et al. Dreaming in Christianity and Islam. New Brunswick: Rutgers University Press; 2009. 280 p.

8. Carter Chris. Science and the Afterlife Experience, Evidence for the Immortality of Consciousness. Rochester Vermont; Inner Traditions; 2012. $384 \mathrm{p}$.

9. Cavicchi D. Tramps like Us: Music and Meaning among Springsteen Fans. Oxford: Oxford University Press; 1998. 11 p.

10. Chiang Phyllis. Fluid knowledge. Unpublished paper. 2014.

11. Cooke Deryck. The Language of Music. Oxford: Oxford University Press; 1959. 304 p.

12. De Nora Tia. Music in Everyday Life. Cambridge: Cambridge University Press; 2000.181 p.

13. Dossey Larry. 7 billion minds or one? Huffington Post. 2013a.

14. Feld Steven. Sound and Sentiment. USA: University of Pennsylvania Press; 1990. 38 p.

15. Finnegan Ruth. Etrancementb: The Consciousness of Dreaming, Musuc and the Workd. Cardiff: University if Wakes Press; 2017. 293 p.

16. Frith Simon. Performing Rites. Oxford: Oxford University Press; 1996. $360 \mathrm{p}$.

17. Guggenheim Bill, Guggenheim Judy. Hello from Heaven. New York: Bantam; 1995. 416 p.

18. Hardy Barbara. Tellers and Listeners Narrative Imagination. London: Continuum; 1968. 279 p.

19. Heaney Nicholas. The Silence at the Song's End. Newyork: Songsend Books; 2007. 117 p.

20. Howes David. The Sixth Sense Reader. Oxford: Berg; 2011. 388 p. 
21. Inglis. Fred Cultural Studies. Oxford: Blackwell; 1993. 262 p.

22. Janis, Byron. Chopin and Beyond: My Extraordinary Life in Music and the Paranormal. Hoboken: Wiley; 2010. 219 p.

23. Krippner Stanley, Fracasso Cheryl. Dreams, telepathy and various states of consciousness. Neuro Quantology. 2011;9(1):1-4.

24. Leppert Richard. The Sight of Sound, Music, Representation and the Body. Berkeley: University of California Press; 1991. 346 p.

25. Lutz CA, White G. The anthropology of emotions. Annual Review of Anthropology. 1986;15:405-436.

26. McGilchrist Iain. The Master and his Emissary. Then Divided Brain and the Making of the Western Workd. Hardcover: Yale University Press; 2012. 608 p.

27. Meyer Leonard. Emotion and Meaning in Music. Chicago: University of Chicago Press; 1956. 315 p.

28. Ostwald Peter F. Semiotics of Human Sound. Berlin: Mouton de Gruyter; 1973. $422 \mathrm{p}$

29. Ottenberg Simon. Seeing with Music, the Lives of Three Blind African Musicians. Seattle: University of Washington Press; 1996. 216 p.

30. Radin Dean. The Noetic Universe. The Scientific Evidence for Psychic Phenomena. London: Tran world; 1997.408 p.

31. Rouget G. Music and Trance. A Theory of the Relations between Music and Possession. Chicago: University of Chicago Press; 1985. 418 p.

32. Schafer Murray. The Tuning of the World. New York: Randim House; 2003. $288 \mathrm{p}$.
33. Schutz A. Making music together. Social Research. 1951;18(1):76-97.

34. Stoller P. Sound in Songhay cultural experience. American Ethnologist. 1984;11(3):559-570.

35. Targ Russell. The Reality of ESP. A Physicist's Proof of Psychic Abilities. Wheaton: Theosophical Publishing House; 2012. 363 p.

36. Tart Charles T. The End of Materiality. Oakland: Harbinger Books; 2009. $20 \mathrm{p}$.

37. Tedlock, Barbara. Dreaming: Anthropological and Psychological Interpretations, Santa Fé, School of American Research Press; 1987. 297

38. Truax B. Acoustic Communucation. Norwood: Ables; 1984. 17 p.

39. Turner Vic, Bruner Jerome. The Anthropology of Experience. Urbana: University of Illinois Press; 1986. 400 p.

40. Van Leeuwen T. Speech, Music Sound. Basingstoke: Macmillan; 1999. $231 \mathrm{p}$.

41. Van Lommel Pim. Consciousnesses beyond Life. The Science of the Near-Death Experience. USA: Harper One; 2011. 280 p.

42. Vedfelt Ole. The Dimensions of Dreams from Freud. New York: Fromm International; 1999. 448 p.

43. Wagner Stephen. Twin telepathy: the best evidence. 2012.

44. Williams S. Emotion and Social Theory. Corporeal Reflections on the (Ir) Rational. London: Sage; 2000. 119 p.

45. Zangrilli Quirino. iDream and telepathy, Science and Psychoanalysis. 2012. 